\title{
Gene expression associated with the onset of hearing detected by differential display in rat organ of Corti
}

\author{
Ellen Reisinger ${ }^{\star 1}$, David Meintrup ${ }^{2}$, Dominik Oliver ${ }^{1,3}$ and Bernd Fakler ${ }^{1}$
}

The exquisite performance of the mammalian hearing organ results from a finely orchestrated array of cell types, and their highly specialized functions are determined by their gene expression profile. In rodents, this profile is established mainly during the first 2 weeks of postnatal maturation. In this paper, we used the differential display technique on the rat organ of Corti to uncover transcripts upregulated in expression between postnatal stages P0 and P14. A total of 176 different genes were identified, the mRNA amount of which increased during early postnatal development. The transcripts code for proteins serving a broad spectrum of cellular functions including intracellular signaling, control of growth/differentiation, regulation of protein synthesis/degradation/modification, metabolism and synaptic function. In addition, the set of upregulated transcripts contained several proteins of yet unknown function, as well as hypothetical proteins and so far unknown mRNA sequences. Thus, this study unravels the broad and specific transcription program that operates the maturation of the mammalian hearing organ. Further, as 49 of the genes found here map to at least one unspecified deafness locus, our study provides candidate genes for these and novel deafness loci.

European Journal of Human Genetics (2010) 18, 1327-1332; doi:10.1038/ejhg.2010.111; published online 21 July 2010

Keywords: deafness genes; hair cells; quantitative real-time PCR; deafness loci; hair cell differentiation

\section{INTRODUCTION}

The mammalian hearing organ, the cochlea, perceives and processes sound with extremely high sensitivity and frequency selectivity. ${ }^{1}$ This remarkable performance essentially results from the concerted action of various highly specialized cell types that are organized in a wellordered microarchitecture and serve quite a number of distinct functions, including ion transport and homeostasis, micromechanics and active amplification, sensory transduction and electrical signal propagation. ${ }^{1,2}$

At the molecular level, this specialization, and hence perception and processing of sound, relies on the expression of a multitude of proteins, some of them specifically found in the inner ear, eg, tectorin, cochlin and prestin. ${ }^{3-6}$ This notion is supported by the considerable number of genes shown to be causative for inherited, nonsyndromic forms of hearing impairment or deafness, both in humans and mouse models. ${ }^{7,8}$ Furthermore, a series of proteins found both in the inner ear and in other tissues are known to be causative for inherited diseases that are associated with deafness. For example, Usher syndrome proteins such as SANS are required for the proper function of auditory hair bundles and photoreceptors in the retina. ${ }^{9}$ For humans, the central database has so far collected more than 140 different gene loci associated with nonsyndromic deafness. ${ }^{10,11}$ However, until now, only around 50 have been assigned to proteins with defined function, and the majority still await identification and examination of the respective molecular pathomechanism. ${ }^{10-12}$

In rodents, pups are born deaf and the inner ear undergoes extensive remodeling during postnatal development, ${ }^{13}$ culminating in the onset of hearing around postnatal day 12 (P12) in rats. ${ }^{14}$
Accordingly, proteins essential for perception and processing of sound are expected to be 'switched on' or to be upregulated at the transcriptional level during this period. Known examples that confirm this developmental pattern and cause inherited hearing disorders in humans when mutated include prestin (SLC26A5), ${ }^{15-17} \mathrm{KCNQ}^{18}$ and Cav1.3.7,8,19,20 Thus, postnatal maturation renders the rat organ of Corti as an ideal model system for investigating genes required for hearing by analysis of transcripts being differentially expressed before and after the onset of hearing. The differential display on cDNA (cDNA-DD) of microdissected organs of Corti showed several benefits for our experimental design: first, it requires only small amounts of tissue without the need for a preliminary step to amplify mRNA or cDNA. Indeed, the high sensitivity of the cDNA-DD technique might increase the chance of detecting expression differences for low abundance transcripts that are underrepresented in DNA array outcomes. ${ }^{21}$ Second, cDNA-DD allows detecting not only genes with database entries but also new mRNA transcripts or splice variants. Third, several previous studies proved the reliability and robustness of cDNA-DD. ${ }^{22-24}$

In this study, we used cDNA-DD to identify genes that are upregulated in the rat organ of Corti between the very immature postnatal stage $\mathrm{P} 0$ and $\mathrm{P} 14$, which is 2 days after the onset of hearing.

\section{MATERIALS AND METHODS}

Differential display

Tissue preparation. Organs of Corti from six rats at day of birth and apical parts of the organs of Corti of seven rats at postnatal stage P14 were dissected under 5- to 10-fold magnification and immediately frozen in liquid nitrogen

\footnotetext{
${ }^{1}$ Institute of Physiology II, University of Freiburg, Hermann-Herder-Straße 7, D-79104 Freiburg, Germany; ${ }^{2}$ Department of Mechanical Engineering, University of Applied Sciences Ingolstadt, Ingolstadt, Germany

*Correspondence: Dr E Reisinger. Current address: Molecular Biology of Cochlear Neurotransmission Junior Research Group, InnerEarLab, University Medical Center Göttingen, Robert-Koch-Straße 40, D-37099 Göttingen, Germany. Tel: +49-551-3922837 or +49-551-39 9688; Fax: +49-551-39-12950; E-mail: ereisin@gwdg.de ${ }^{3}$ Current address: Institute of Physiology and Pathophysiology, Philipps-Universität Marburg, Deutschhausstraße 2, D-35037 Marburg, Germany.

Received 7 September 2009; revised 20 May 2010; accepted 9 June 2010; published online 21 July 2010
} 
before mRNA isolation. Dissected tissue consists of the organ of Corti and minor parts of stria vascularis and spiral ganglion.

mRNA isolation and cDNA synthesis. mRNA was prepared with DYNABeads (Dynal, Oslo, Norway) according to the manufacturer's instructions. mRNA concentrations in $\mathrm{P} 0$ and P14 samples were determined using UV absorption. cDNA was derived using reverse transcription of $\sim 150 \mathrm{ng}$ mRNA (each) with Superscript II (Invitrogen, Karlsruhe, Germany) in supplemented buffer and $10 \mu \mathrm{m}$ DTT, $1 \mathrm{~mm}$ dNTPs, 1 pmol oligo-dT-primer and $0.3 \mu \mathrm{l}$ RNasin (Promega, Madison, WI, USA) for $2 \mathrm{~h}$ at $42^{\circ} \mathrm{C}$.

Differential display. The differential display on reverse transcribed mRNA of $\mathrm{P} 0$ and P14 organs of Corti was performed as described. ${ }^{25}$ Briefly, arbitrary $P$-primers of the 'Delta Differential Display' kit (Clontech, Palo Alto, CA, USA) were combined with each other or with two-base-anchored oligo-dT-primers.

The differential display PCR was set up with two dilutions of reverse transcribed P0 and P14 mRNA (dilution A, using $2.4 \mathrm{ng} / \mu \mathrm{lmRNA}$; dilution B, using $0.6 \mathrm{ng} / \mu \mathrm{l} \mathrm{mRNA}$ ) and for negative controls with mRNA (without reverse transcriptase) or $\mathrm{H}_{2} \mathrm{O}$ as templates.

Bands from P14 cDNA with no corresponding band at P0 cDNA, or bands with higher intensity in both dilutions of P14 template cDNA compared with both P0 lanes, were considered as 'differential. The underlying gel pieces were cut out, DNA was eluted in $40 \mu \mathrm{l} 1 \times \mathrm{TE}$ at $100^{\circ} \mathrm{C}$ for $5 \mathrm{~min}$ and reamplified by a PCR using the original primer combination and 20-25 cycles of a standard PCR protocol.

Identification of cDNA bands. Reamplified DNA fragments were analyzed by direct sequencing with fluorescent dye terminator cycle sequencing (Applied Biosystems, Weiterstadt, Germany). cDNAs for which no sequence information was obtained with this procedure were subcloned into pBluescript $\mathrm{SK}^{-}$(Agilent Technologies, Santa Clara, CA, USA) and three to five clones of each subcloned band were sequenced. In Supplementary Tables 2 and 3, only those genes were included in which at least two inserts from independent clones were comprised of identical or overlapping sequences.

\section{Quantitative real-time PCR}

RNA preparation and reverse transcription for quantitative PCR (qPCR) analysis. Transcripts from the inner ear were quantified as described. ${ }^{26}$ mRNA of the respective developmental stage was prepared two times independently from the apical turns of six or seven organs of Corti. Total RNA was isolated with Trizol reagent (Invitrogen) as recommended by the manufacturer. RNA was transcribed into cDNA in $1 \times$ first strand buffer with $10 \mu \mathrm{M}$ DTT, $0.5 \mathrm{~mm}$ dNTPs, $0.3 \times$ hexanucleotide Mix (Roche, Mannheim, Germany), $50 \mathrm{pmol}$ oligo-dT-primer, $20 \mathrm{U}$ RNasin (Promega) and $1 \mu \mathrm{l}$ Superscript II (Invitrogen) for $10 \mathrm{~min}$ at $25^{\circ} \mathrm{C}, 10 \mathrm{~min}$ at $37^{\circ} \mathrm{C}$ and for $70 \mathrm{~min}$ at $42^{\circ} \mathrm{C}$. These cDNA samples were ethanol precipitated before qPCR.

Design of intron-overspanning primers. Primer pairs were designed by means of Primer Express 2.0 software (Applied Biosystems). Primers were either placed on neighboring exons, when introns spanned more than $1 \mathrm{~kb}$, or one of the primers annealed over the intron splice site so that five to eight nucleotides on the $3^{\prime}$ site bound to the downstream exon. Amplification efficiency was evaluated in a separate GPCR experiment, followed by melting curve analysis. Primer sequences are given in Supplementary Table 1.

Real-time qPCR. Quantitative PCR was performed with SYBr Green (2×Master Mix, Applied Biosystems) in an ABI PRISM 7000 or 7500 sequence detection system (Applied Biosystems). For the quantification of 18S rRNA, samples were diluted 1:100 or 1:1000. All qPCR experiments were conducted in triplicate; $S D$ s of $C_{t}$ values were on average 0.12 cycles, which reflects an SD in cDNA copy numbers of $5.3 \%$. The SDs were smaller for high abundance genes, eg, $18 \mathrm{~S}$ rRNA quantification resulted in an SD of 0.02 cycles or $1.5 \%$ SD for the number of mRNA molecules, but higher for low abundance genes, eg, Scamp3 ( $\mathrm{C}_{\mathrm{t}}$ values between 35 and 38 , which is close to the detection limit).

To calculate mean $C_{t}$ values, nonlogarithmic numbers $\left(2 \wedge\left(42-C_{t}\right)\right)$ were calculated, which were then averaged and back-calculated to obtain the (logarithmic) $\mathrm{C}_{\mathrm{t}}$ value. Transcript abundance in each sample was determined using the comparative $\mathrm{C}_{\mathrm{T}}$ method, as described. ${ }^{26,27}$

\section{RESULTS}

Profiling upregulated transcripts using cDNA-DD

In this study, we used a cDNA-DD with reverse transcribed mRNA of P0 and P14 organs of Corti to identify genes upregulated during postnatal development in the rat hearing organ (Figure 1A). In all, 28 combinations of 'arbitrary' and 'oligo-dT' primers were used for PCR amplification of cDNA fragments from both transcriptomes. Separation of the radioactively labeled PCR products on highresolution acrylamide gels showed distinct patterns between the two postnatal stages (Figure 1B) and allowed for identification of cDNA fragments with higher abundance in P14 amplifications. Altogether, 302 cDNA fragments were found to be upregulated in P14 organs of Corti, of which 289 were successfully recovered from the gel and reamplified. Of these, 166 allowed for direct sequencing, whereas 115 cDNA fragments were identified only after subcloning. In all, 14 of the subcloned fragments contained more than one DNA sequence (according to the criteria described in Materials and methods). In total, sequences of 297 cDNA fragments were assigned to differential bands.

\section{Identification and categorization of transcripts}

All sequences were screened for redundancy by comparison against each other (using $F A S T A^{28}$ ) and against the public 'nonredundant' or 'expressed sequence tag' databases on www.ncbi.nlm.nih.gov using $B L A S T{ }^{29}$ In total, 176 individual genes were detected by this cDNA-DD, of which 114 were identified by cDNA fragments found in one cDNA-DD band each, whereas 62 genes were covered by DNA fragments extracted from two to eight bands (Table 1).

From the 176 genes, 116 fragments could be attributed to genes with a well-established function (Figure 2a, Supplementary Table 2). Another 19 sequences originated from genes encoding proteins with unknown function, whereas $13 \mathrm{cDNA}$ fragments were assigned to predicted or hypothetical proteins. Further, 20 sequences matched to expressed sequence tags or uncharacterized mRNA sequences (Figure 2a), with two significantly exceeding database entries, which were therefore submitted for publication (dbEST 50172343, 50172344). Eight sequences were deposited in public databases (accession numbers 50172335-50172342) as they did not match any database entry for transcribed sequences, but corresponded to genomic DNA entries.

The proteins with known function were grouped with respect to their role in cell physiology (Figure 2b). As summarized in Supplementary Table 2, a substantial fraction of the developmentally upregulated genes are involved in (1) intracellular signaling pathways (including kinases/phosphatases and interacting molecules, GTP-binding proteins, receptors and enzymes modifying second messengers), as well as in (2) extracellular signaling dedicated mainly to regulation of growth and differentiation and in (3) transmembrane signaling and transport represented by subunits of ion channels and solute carriers. Further functional categories defined by the identified transcripts are (4) synaptic/vesicular proteins, (5) proteins involved in regulation of protein biosynthesis and degradation (including transcriptional elements, chaperones and components of protein degradation machineries), and (6) proteins involved in maintenance of the cellular (sub-) structure and morphology. In addition, quite a number of the identified gene products show enzymatic activities (7) and participate in metabolism of various subcellular compartments (see Supplementary Table 2).

Together, the diversity of gene products detected by our cDNA-DD approach showed that maturation of the hearing organ requires a broad transcriptional program covering various cell physiological functions. 
a

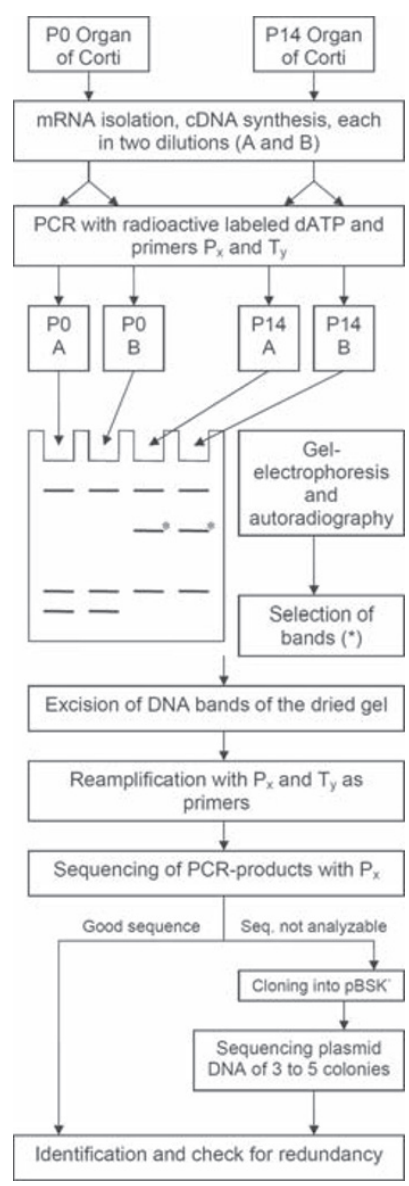

b

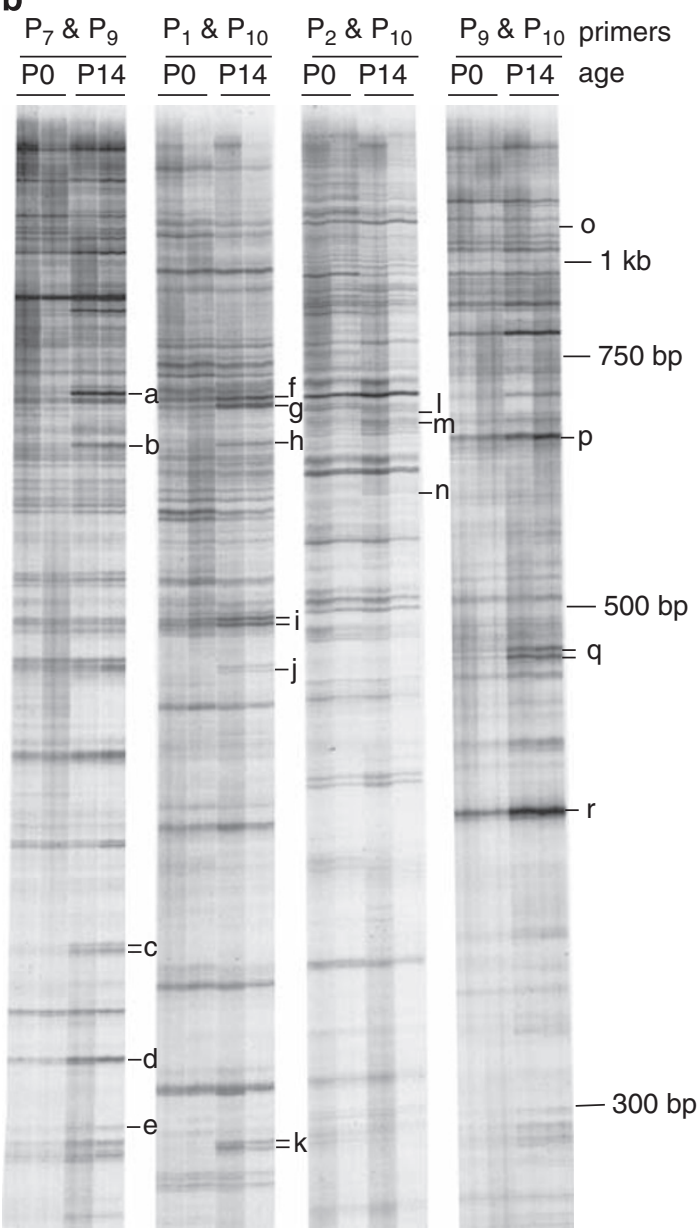

Figure 1 cDNA-DD on the developing rat organ of Corti. (a) Flowchart of the CDNA-DD. (b) Radioactively labeled cDNA fragments were amplified and separated on a high-resolution acrylamide gel. A PCR using a combination of two primers results in four neighboring lanes, in which two different cDNA concentrations (higher on left, lower on right) from postnatal day 0 (PO) and P14 were used as templates. Small letters indicate bands with higher abundance in P14 compared with P0; examples for bands identified by cycle sequencing are (a) Kcnj16, (b) mineralocorticoid receptor, (c) glutaredoxin, (d) annexin A2, (e) $\mathrm{Ca}^{2+} \mathrm{bp}$ P22 (Chp), (f and $r$ ) transcribed sequences Rn.4180, (g) Na+/K+-ATPase- $\beta 1$, (h and m) Snap91, (i) SLC20A1, (j) sphingolipid$\Delta 4$-desaturase, (k) Na+/K+-ATPase- $\alpha 3$, (I) CUG-BP1, (n) Cpeb1, (o) annexin A5, (p) cathepsin B and (q) transcribed sequences Rn.48946, similar to human hypothetical protein KIAA0256.

\section{Table 1 Gene frequency}

\begin{tabular}{lrr}
\hline Frequency & Genes & Bands \\
\hline 1 & 114 & 114 \\
2 & 38 & 76 \\
3 & 12 & 36 \\
4 & 2 & 8 \\
5 & 3 & 15 \\
6 & 3 & 18 \\
7 & 2 & 14 \\
8 & 2 & 16 \\
$\geqslant 9$ & 0 & 0 \\
Total & 176 & 297 \\
\hline
\end{tabular}

The table shows the frequency with which genes were identified within this cDNA-DD.

\section{Association of differential genes with hearing disorders}

Some proteins found in this study to be upregulated during inner ear maturation had been assigned to hearing disorders. Three of the genes, namely, Sbf2, Pmp22 and myelin protein zero, lead to variants in Charcot-Marie-Tooth Syndromes, which are associated with hearing impairment. $^{30,31}$ In a mouse model, deficiency in neurotrophic tyrosine kinase receptor type 2 was shown to be emybronic lethal, and also led to a defect in hair cell innervation. ${ }^{32,33}$ In addition, for a series of genes identified here, a close protein family member had been shown to cause deafness in humans. For example, protocadherin 15, sharing $42 \%$ sequence similarity with protocadherin- $\alpha$ (Supplementary Table 2, section II), is now well established to cause Usher $1 \mathrm{~F}$ syndrome $\mathrm{s}^{34,35}$ and DFNB23. ${ }^{36}$

We next compared the genetic locus of human homologous genes with deafness loci that had not been associated with a specific gene. If the position of the human gene lay within the finite linked deafness loci defined by linkage analysis, we considered this gene to be a potential candidate for a deafness gene. We found 49 genes that matched these criteria and were at the same time not assigned to a genetic human disorder in OMIM database (Supplementary Table 3). For example, two genes with a yet unknown function, namely, reticulon 3 and transmembrane protein $16 \mathrm{~A}$, both match to the 

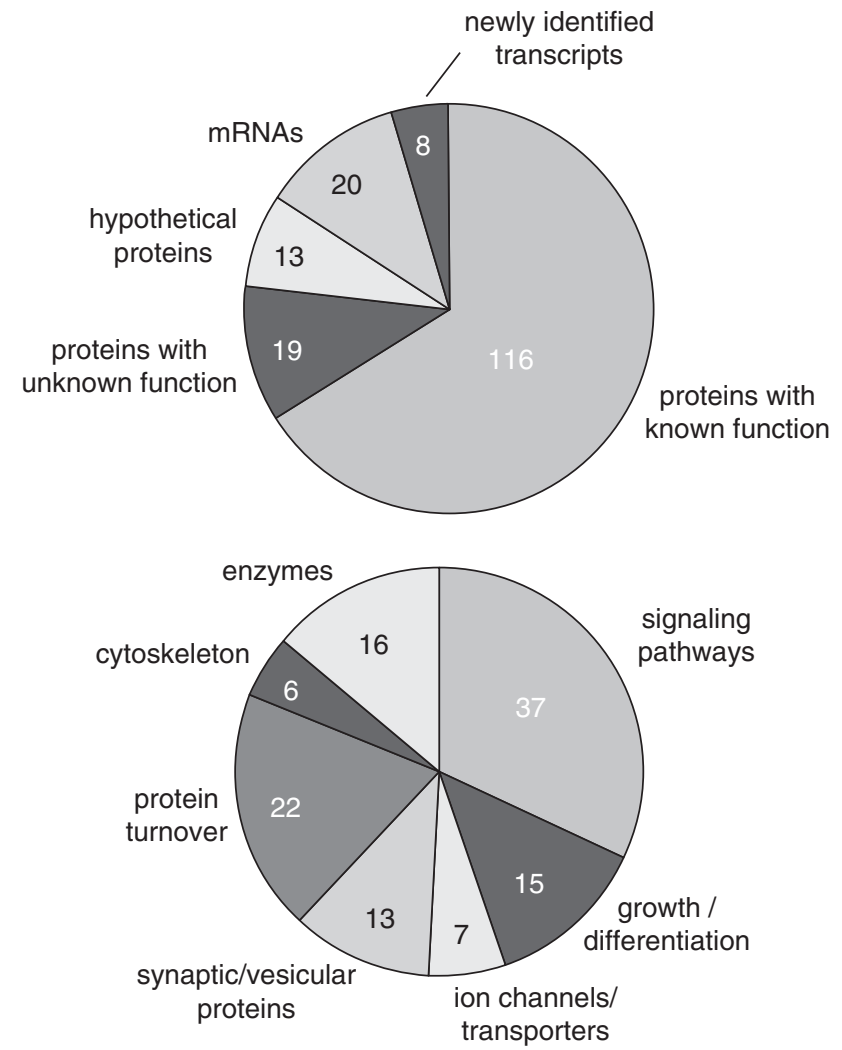

Figure 2 Summary of CDNA-DD results. (a) Alignments of the sequences with entries in the public databases reveal the fraction of proteins of known function vs less characterized genes. (b) Proportions of the cellular functions of the 116 proteins of known function identified in this CDNA-DD.

deafness locus DFNB63, whereas in the genomic region comprising deafness loci DNFNA24, DFNA27 and DFNB55, insulin-like growth factor binding protein 7 (Igfbp7) is encoded.

\section{Upregulation of transcripts in the postnatal period}

The transcriptional upregulation implied in the cDNA-DD approach was verified in experiments that quantified postnatal expression by qPCR. For this validation experiment, we selected genes matching several deafness loci, different genes encoded within the same deafness locus and genes that might have an important role in organ of Corti function. The qPCR experiments revealed a substantial upregluation between P0 and P14 for 21 out of the 27 tested genes (Figure 3a). Upregulation was more than fivefold for seven genes, including Igfbp7, Na-K-ATPase- $\beta 3$ and Sepp1, the human genes of which lie within several deafness loci. With this approach, we could not find a significant upregulation for Rab9, protocadherin- $\alpha$, transmembrane protein 16A, prefoldin, Prkab2 and pleiotrophin.

For five genes, we tested the course of upregulation during five postnatal developmental stages of the organ of Corti (Figure 3b). SLC20A1 was found to show a linear increase in mRNA level between P0 and P21, whereas SNAP91 and Mpp6 show transient upregulation with peak levels around P10. mRNA expression of Chp ( $\left.\mathrm{Ca}^{2+} \mathrm{bp}-\mathrm{P} 22\right)$ and Gpm6b elevates between postnatal days 1 and 9 and remains almost constant thereafter (Figure $3 \mathrm{~b}$ ). Thus, the upregulation of individual genes seems to occur at different time points during postnatal maturation of the inner ear.

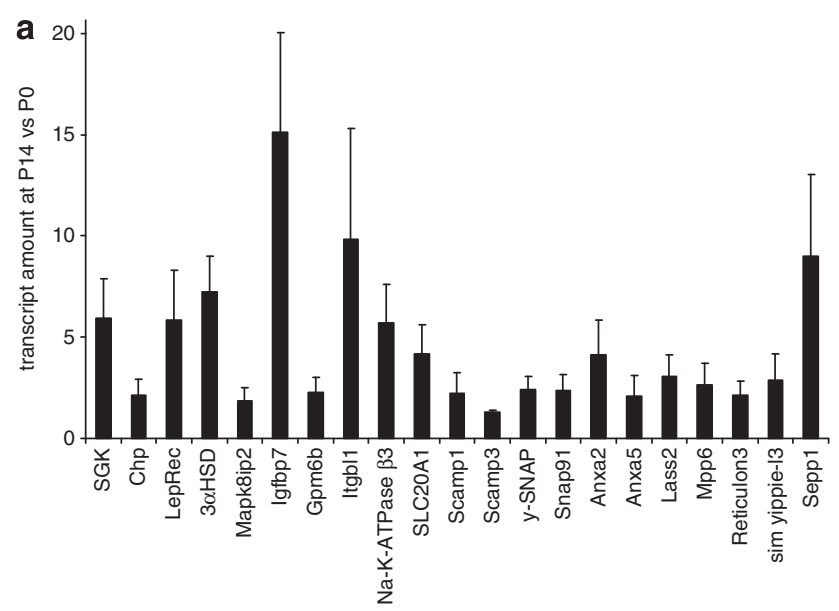

b

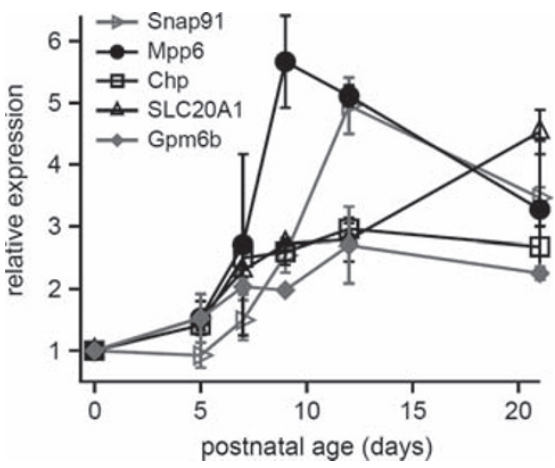

Figure 3 Upregulation was quantified with quantitative PCR. (a) mRNA from two times six organs of Corti from PO and P14 rats was isolated and reverse transcribed. qPCR with SYBr green was pipetted in triplicates for each of the four cDNA samples and for each pair of intron-overspanning primers. cDNAs were normalized on 18S rRNA (dilution of template DNA 1:1000). Bar graphs show the mean amount of cDNA at P14 compared with PO. Standard errors of the mean (SEM) are calculated from the relative CDNA amounts in the four cDNA preparations (compared one by one). (b) Time course of mRNA upregulation in the apical turn of the rat organ of Corti determined for a sample set of genes (mean \pm SEM).

\section{Estimation of completeness of results}

The identification of 176 distinct proteins led to the question of how many genes may actually be upregulated in the maturating organ of Corti in total. We estimated this by statistical analysis using a custom developed algorithm, ${ }^{25}$ which is based on the correlation that redundancy of randomly amplified genes decreases when the total number of templates increases.

We estimated that $16 \%$ ( $90 \%$ confidence interval of $0.145,0.178$ ) of genes expressed in the organ of Corti are upregulated during postnatal maturation. Further, 441 differentially expressed genes are estimated to be theoretically detectable by cDNA-DD using an infinite number of primer combinations ( $90 \%$ confidence interval: $397,485)$. Accordingly, the cDNA-DD with a subset of 28 primer combinations that identified 176 distinct genes uncovered $\sim 40 \%$ of the accessible differentially expressed genes. Finally, the total number of genes expressed in the organ of Corti is estimated to be 2734 (90\% confidence interval: 2485,3037$)$. We consider this estimation as a lower limit for the actual protein encoding genes in the rat organ of Corti because of limitations of the cDNA-DD technique (discussed in ${ }^{25}$ ). 


\section{DISCUSSION}

In this study, we identified a set of transcripts that are upregulated during postnatal maturation of the organ of Corti. The massive change in gene expression probably underlies the extensive physiological and morphological changes that lead to maturation steps essential for the onset of hearing.

\section{Reliability of the method}

To uncover differentially expressed transcripts in the mammalian inner ear, we chose the cDNA-DD method mainly because of its high sensitivity. Indeed, we successfully detected genes with low copy numbers, such as Itgbl1 or Scamp3 (according to qPCR), and a series of 11 transcription factors. Further, this approach is known to produce a low fraction of false positives, which was reassessed here by $\mathrm{qPCR}$. Although 21 out of 27 genes were confirmed to be substantially upregulated (Figure 3), transcript levels of six genes were unchanged in these experiments. This could be due to differences in organ of Corti microdissections between cDNA-DD and qPCR. For example, if a gene is upregulated in hair cells, but downregulated in spiral ganglion neurons, different amounts of spiral ganglion tissue attached to the organ of Corti in the different preparations could lead to such discrepancies.

Applying the cDNA-DD approach, we uncovered differences in mRNA expression, assuming that transcript abundance correlates with protein amounts for most of the genes. This presumption was found to be supported by earlier findings on the developmental upregulation of gene products involved in cochlear function. For example, immunostaining for KCNJ16 (Supplementary Table 2, section III) showed a rapid increase in protein levels in the rat cochlea from P10 to P16, correlating with observed changes in endocochlear potential. ${ }^{37}$ Another well-studied example is the polyamine metabolism (Supplementary Table 2, section If): highest ornithine decarboxylase activity was observed at postnatal days 9 and 10, and it declined to about $1-2 \%$ in adulthood. ${ }^{38,39}$ Moreover, deficiency in spermine synthase, an enzyme functioning in this pathway, was shown to cause deafness in mice. ${ }^{40}$ These examples strongly support the idea that differential transcripts found in our study might indeed reflect a postnatal upregulation of the respective proteins in the rodent inner ear.

In summary, the cDNA-DD approach turned out to reliably uncover upregulated transcripts in the inner ear. However, some proteins such as KCNQ4, prestin or TMC1, have not been detected by this approach, despite our expectation to do so. For KCNQ4, the mRNA of which has a GC content of $62 \%$, we assume that it would not be amplified under our experimental conditions, but only on addition of DMSO. Other proteins might have been missed, as this cDNA-DD uncovered only $40 \%$ of detectable genes.

\section{Significance for identification of deafness genes and cochlear biology}

Normal hearing requires proper expression and function of an extensive set of specialized proteins, a notion reflected in the high number $(\sim 140)$ of gene loci correlated with various forms of nonsyndromic hearing loss. Currently, 90 of these loci, mostly spanning 100 genes or more, ${ }^{10,12,41}$ still await identification of the gene underlying this particular form of deafness. It is reasonable to suggest that in rodents many of those genes should be upregulated between birth and the onset of hearing. Here, we found 49 upregulated genes that have not yet been described as disease associated, but lie within a human deafness locus with a so far unidentified underlying gene. Therefore, they are attractive candidates for geneticists that aim to identify genes defective in the respective forms of deafness. Further, interaction partners of the proteins unraveled here - although not directly identified in this study - might also be reasonable candidate genes for deafness loci.

Apart from the added value of our study for identification of candidate genes in novel deafness loci, this study gives insight into the molecular machinery that enables the organ of Corti to transduce mechanical energy into electrical energy. The series of proteins serving most different cellular functions (Supplementary Table 2) might inspire research on different aspects of cochlear biology, such as establishment of the cytoskeleton, inter- and intracellular signaling and regulation of gene activation by transcription factors.

In this study, we show that maturation of the mammalian cochlea is associated with the transcriptional upregulation of several proteins implicated in a wide array of cellular functions in the inner ear. Notably, many of the 176 distinct genes identified here match to so far uncharacterized deafness loci. Thus, this study provides a rational set of target candidates for deafness genes within deafness loci that often span more than 100 genes. $^{41}$

\section{CONFLICT OF INTEREST}

The authors declare no conflict of interest.

\section{ACKNOWLEDGEMENTS}

We thank Susanne Weidemann, Nina Katrin Dankenbrink-Werder and Jost Ludwig for technical assistance and advice; Henrike Berkefeld for help with the preparation of organs of Corti; and Tina Pangrsic, Tobias Moser and Nikolaj Klöcker for critically reading the paper. The project was supported by the Graduiertenkolleg GRK 843.

1 Dallos P: The active cochlea. J Neurosci 1992; 12: 4575-4585.

2 Hudspeth AJ: How hearing happens. Neuron 1997; 19: 947-950.

3 Weber T, Zimmermann $\mathrm{U}$, Winter $\mathrm{H}$ et al: Thyroid hormone is a critical determinant for the regulation of the cochlear motor protein prestin. Proc Natl Acad Sci USA 2002; 99: 2901-2906.

4 Zheng J, Long KB, Matsuda KB, Madison LD, Ryan AD, Dallos PD: Genomic characterization and expression of mouse prestin, the motor protein of outer hair cells. Mamm Genome 2003; 14: 87-96.

5 Li L, Ikezono T, Watanabe A, Shindo S, Pawankar R, Yagi T: Expression of full-length Cochlin p63s is inner ear specific. Auris Nasus Larynx 2005; 32: 219-223.

6 Killick R, Richardson GP: Antibodies to the sulphated, high molecular mass mouse tectorin stain hair bundles and the olfactory mucus layer. Hear Res 1997; 103: 131-141.

7 Petit C, Levilliers J, Hardelin JP: Molecular genetics of hearing loss. Annu Rev Genet 2001; 35: 589-646.

8 Steel KP, Kros CJ: A genetic approach to understanding auditory function. Nat Genet 2001; 27: 143-149.

9 Weil D, El-Amraoui A, Masmoudi S et al: Usher syndrome type I G (USH1G) is caused by mutations in the gene encoding SANS, a protein that associates with the USH1C protein, harmonin. Hum Mol Genet 2003; 12: 463-471.

10 Van Camp G, Smith RJH: Hereditary Hearing Loss Homepage 2010. Available online at: http://hereditaryhearingloss.org/.

11 Dror AA, Avraham KB: Hearing loss: mechanisms revealed by genetics and cell biology. Annual Review of Genetics 2009; 43: 411-437.

12 Friedman TB, Griffith AJ: Human nonsyndromic sensorineural deafness. Annu Rev Genomics Hum Genet 2003; 4: 341-402.

13 Pujol R, Lavigne-Rebillard M, Lenoir M: Development of Sensory and Neural Structures in the Mammalian Cochlea; in: Rubel EW, Popper AN, Fay RR (eds): Development of the auditory system. Springer: New York, 1997, pp 146-192.

14 Rübsamen R, Lippe WR: The development of cochlear function; in: Rubel EW, Popper AN, Fay RR (eds): Development of the Auditory System. Springer: New York, 1997, pp 193-270.

15 Toth T, Deak L, Fazakas F, Zheng J, Muszbek L, Sziklai I: A new mutation in the human pres gene and its effect on prestin function. Int J Mol Med 2007; 20: 545-550.

16 Liu XZ, Ouyang XM, Xia XJ et al: Prestin, a cochlear motor protein, is defective in non-syndromic hearing loss. Hum Mol Genet 2003; 12: 1155-1162.

17 Oliver D, Fakler B: Expression density and functional characteristics of the outer hair cell motor protein are regulated during postnatal development in rat. J Physiol 1999; 519 (Part 3): 791-800. 
18 Beisel KW, Nelson NC, Delimont DC, Fritzsch B: Longitudinal gradients of KCNQ4 expression in spiral ganglion and cochlear hair cells correlate with progressive hearing Ioss in DFNA2. Brain Res Mol Brain Res 2000; 82: 137-149.

19 Brandt A, Striessnig J, Moser T: CaV1.3 channels are essential for development and presynaptic activity of cochlear inner hair cells. J Neurosci 2003; 23: 10832-10840.

20 Hafidi A, Dulon D: Developmental expression of $\mathrm{Ca}(\mathrm{v}) 1.3$ (alpha1d) calcium channels in the mouse inner ear. Brain Res Dev Brain Res 2004; 150: 167-175.

21 Hildebrand MS, de Silva MG, Klockars T, Campbell CA, Smith RJH, Dahl H-HM: Gene expression profiling analysis of the inner ear. Hearing Research 2007; 225: $1-10$.

22 Stankovic KM, Corfas G: Real-time quantitative RT-PCR for low-abundance transcripts in the inner ear: analysis of neurotrophic factor expression. Hear Res 2003; 185: 97-108.

23 Liang P, Pardee AB: Differential display of eukaryotic messenger RNA by means of the polymerase chain reaction. Science 1992; 257: 967-971.

24 Diachenko LB, Ledesma J, Chenchik AA, Siebert PD: Combining the technique of RNA fingerprinting and differential display to obtain differentially expressed mRNA. Biochem Biophys Res Commun 1996; 219: 824-828.

25 Meintrup D, Reisinger E: A statistical model providing comprehensive predictions for the mRNA differential display. Bioinformatics 2005; 21: 3880-3886.

26 Reisinger $E$, Zimmermann $U$, Knipper $M$ et al: Cod106, a novel synaptic protein expressed in sensory hair cells of the inner ear and in CNS neurons. $\mathrm{Mol} \mathrm{Cel} \mathrm{NeurosCi}$ 2005; 28: 106-117.

27 Livak KJ, Schmittgen TD: Analysis of relative gene expression data using real-time quantitative PCR and the 2deltadeltaCT method. Methods 2001; 25: 402-408.

28 Pearson WR, Lipman DJ: Improved tools for biological sequence comparison. Proc NatI Acad Sci USA 1988; 85: 2444-2448.

29 Altschul SF, Madden TL, Schaffer AA et al: Gapped BLAST and PSI-BLAST: a new generation of protein database search programs. Nucleic Acids Res 1997; 25: 3389-3402.
30 Chapon F, Latour P, Diraison P, Schaeffer S, Vandenberghe A: Axonal phenotype of Charcot-Marie-Tooth disease associated with a mutation in the myelin protein zero gene. J Neurol Neurosurg Psychiatry 1999; 66: 779-782.

31 Kovach MJ, Lin J-P, Boyadjiev S et al: A unique point mutation in the PMP22 gene is associated with Charcot-Marie-Tooth disease and deafness. Am J Hum Genet 1999; 64: 1580-1593.

32 Fritzsch B, Barbacid M, Silos-Santiago I: The combined effects of trkB and trkC mutations on the innervation of the inner ear. Int J Dev Neurosci 1998; 16: 493-505.

33 Schimmang T, Minichiello L, Vazquez E et al: Developing inner ear sensory neurons require TrkB and TrkC receptors for innervation of their peripheral targets. Development 1995; 121: 3381-3391.

34 Ahmed ZM, Riazuddin S, Bernstein SL et al: Mutations of the protocadherin gene PCDH15 cause Usher syndrome type 1F. Am J Hum Genet 2001; 69: 25-34.

35 Alagramam $\mathrm{KN}$, Yuan $\mathrm{H}$, Kuehn $\mathrm{MH}$ et al: Mutations in the novel protocadherin PCDH15 cause Usher syndrome type 1F. Hum Mol Genet 2001; 10: 1709-1718.

36 Ahmed ZM, Riazuddin S, Ahmad J et al: PCDH15 is expressed in the neurosensory epithelium of the eye and ear and mutant alleles are responsible for both USH1F and DFNB23. Hum Mol Genet 2003; 12: 3215-3223.

37 Hibino $H$, Higashi-Shingai K, Fujita A, Iwai K, Ishii M, Kurachi Y: Expression of an inwardly rectifying $\mathrm{K}+$ channel, $\mathrm{Kir} 5.1$, in specific types of fibrocytes in the cochlear lateral wall suggests its functional importance in the establishment of endocochlear potential. Eur J Neurosci 2004; 19: 76-84.

38 Henley CM: Postnatal developmental changes in inner ear ornithine decarboxylase (ODC). Hearing Research 1991; 55: 45-49.

39 Brock M, Henley CM: Postnatal changes in cochlear polyamine metabolism in the rat. Hear Res 1994; 72: 37-43.

40 Wang X, Levic S, Gratton MA, Doyle KJ, Yamoah EN, Pegg AE: Spermine synthase deficiency leads to deafness and a profound. J Biol Chem 2009; 284: 930-937.

41 Alsaber R, Tabone CJ, Kandpal RP: Predicting candidate genes for human deafness disorders: a bioinformatics approach. BMC Genomics 2006; 7: 180.

Supplementary Information accompanies the paper on European Journal of Human Genetics website (http://www.nature.com/ejhg) 